\title{
ERGONOMIA DO TRABALHO AMBULANTE: ESTUDO DE CASO NA PRAIA CENTRAL DE BALNEÁRIO CAMBORIÚ/SC
}

\section{WORK ERGONOMICS OF BEACH VENDORS: CASE STUDY IN BALNEÁRIO CAMBORIU/SC}

\author{
Franciele Fantini ${ }^{1}$, MsC \\ (1) Universidade do Vale do Itajaí (UNIVALI) \\ e-mail: franfantini@gmail.com
}

Palavras-chave: ergonomia, ambulantes, praia.

Este trabalho, resultante de estudo realizado durante a disciplina de Ergonomia - Epistemologia e Ergonomia parte do mestrado da autora, tem como finalidade analisar, a partir de visitas exploratórias, observações assistemáticas/apreciação ergonômica e inquirição as condições de ergonomia do trabalho ambulantes de vestuário da Praia Central de Balneário Camboriú/SC.

Key-words: Ergonomics, vendors, beach.

This work aims to analyze, based on exploratory visits, unsystematic observations / ergonomic assessment and inquiry through structured interview and Nordic Questionnaire, the ergonomic work conditions of the Balneário Camboriú beach vendor's.

\section{Introdução}

Os ambulantes estão presentes nos ambientes mais distintos como praias, ruas, semáforos e congestionamentos, geralmente em locais ou eventos que reúnem muitas pessoas. Este artigo, resultante de estudo realizado durante a disciplina de Ergonomia - Epistemologia e Ergonomia, parte do mestrado da autora, consiste em analisar as tarefas desenvolvidas por trabalhadores ambulantes que atuam na praia central de Balneário Camboriú, na venda de peças de vestuário, sob a ótica da ergonomia do trabalho, com o intuito de embasar propostas para otimizar o bem-estar humano e o desempenho desta atividade.

\section{Referencial teórico}

Para a elaboração deste artigo foram utilizados campos de conhecimento como a ergonomia, a biomecânica e antropometria, a qual avalia as medidas de tamanho, massa e proporções do corpo 


\section{$16^{\circ}$ \\ ERGODESIGN USIHC CINAHPA}

$16^{\circ}$ Ergodesign - Congresso Internacional de Ergonomia e Usabilidade de Interfaces Humano Tecnológica: Produto, Informações Ambientes Construídos e Transporte

$16^{\circ}$ USIHC - Congresso Internacional de Ergonomia e Usabilidade de Interfaces Humano Computador

CINAHPA | 2017 - Congresso Internacional de Ambientes Hipermídia para Aprendizagem. humano, com o objetivo de analisar os esforços biomecânicos, assim como as posturas inadequadas apresentadas pelos usuários.

Para um maior embasamento, também foram considerados os conhecimentos de Psicologia Ambiental (PA), percepção ambiental e comportamento oriundos da formação em Arquitetura e Urbanismo da autora, de modo que, em complemento aos conhecimentos de ergonomia, se realizasse uma análise da relação entre o homem, sua tarefa e o ambiente na qual ela é desempenhada.

\section{Métodos e técnicas}

Para que se pudessem atingir os objetivos estabelecidos inicialmente, os métodos adotados para a análise ergonômica do trabalho e da psicologia ambiental foram: revisão bibliográfica, visitas exploratórias à Praia Central de Balneário Camboriú, observações assistemáticas/apreciação ergonômica, inquirição através da entrevista estruturada e de Questionário Nórdico.

$\mathrm{Na}$ pesquisa bibliográfica buscou-se compreender e aprofundar referenciais teóricos relacionados à Análise Ergonômica do Trabalho - AET (Montmollin, 1990; Laville, 1993). Esta abordagem tem seu fundamento no modelo elaborado por Guérin et al. (1997), cuja característica central consiste na flexibilidade procedimental na evolução das etapas. Nas visitas exploratórias, conseguiu-se um maior contato com os ambulantes, assim como a percepção do ambiente de trabalho: a praia. Foram realizadas três visitas, sendo que a primeira teve o intuito de se realizar apenas observações assistemáticas para entender o contexto e a atividade para a elaboração do questionário. Tanto na segunda quanto na terceira visita, foram realizados questionários com os ambulantes encontrados.

A inquirição teve o intuito de buscar informações através da entrevista estruturada e foi aplicada para 20 ambulantes, sendo 10 homens e 10 mulheres. Este processo foi realizado individualmente, para evitar direcionamentos ou influências nas respostas dadas. A última etapa da entrevista foi composta por um Questionário Nórdico, o qual teve o objetivo de identificar as moléstias ou incômodos que influenciavam na realização das atividades. Com estes dados em mãos, realiza-se análise e sugere-se algumas recomendações.

\section{Análise dos resultados}

Dispondo do material coletado, foram realizadas análises das observações, entrevistas e questionário realizados, focando nos seguintes aspectos: 0 trabalhador ambulante, o ambiente de trabalho e a atividade realizada. Por fim, abordou-se a problematização decorrente deste processo.

\subsection{O ambulante}

O ambulante é a pessoa que vende produtos ao público, transitando pela multidão, sem que o comprador/cliente precise ausentar-se do seu lugar para adquirir o produto, permitindo, desse modo, a continuidade da atividade sem interrupções.

Dos 20 ambulantes entrevistados, metade deles possui entre 20 e 40 anos e a outra metade de 41 a 60 anos, demonstrado que apesar do grande esforço físico demandado, no grupo pesquisado é uma atividade exercida por trabalhadores de diversas idades.

O grupo entrevistado em sua maioria (55\%) é composto por ambulantes com baixa escolaridade (ensino fundamental) e os outros $45 \%$ completou apenas o ensino médio. Após saírem da escola optaram por essa modalidade de trabalho por falta de oportunidade mercado formal de trabalho (35\%), complemento de uma atividade autônoma na alta temporada ( $45 \%)$, assim como por considerarem que possuem aptidão para esse tipo de trabalho $(20 \%)$.

Analisando tanto o peso quanto a altura média dos ambulantes homens, verificou-se que a maioria possui estatura média e são magros. Já as mulheres também possuem estatura média, mas a maior parte delas está no peso ou acima do peso ideal, apesar do exercício físico realizado diariamente, principamente em decorrência de hábitos alimentares incorretos, uma vez que a maioria não 


\section{$16^{\circ}$ \\ ERGODESIGN USIHC CINAHPA}

realiza sequer intervalos para refeições durante a jornada de trabalho.

Por fim, tratando-se do tempo em que trabalham nesta atividade, mais da metade trabalha como ambulante por 10 anos. Um dado que chamou atenção foi que a maior parte dos entrevistados quando iniciam nesta atividade, apesar do desgaste que ela gera, dificilmente abandonam, principalmente por se tratar de um trabalho secundário, como citado anteriormente, realizado em períodos de férias, onde o trabalho principal, também autônomo, geralmente possui menor procura e menor desgaste, de acordo com os entrevistados.

\subsection{O ambiente $\mathrm{e}$ o trabalho}

O ambiente de trabalho dos ambulantes entrevistados consiste na Praia Central de Balneário Camboriú/SC. Balneário Camboriú está localizado no litoral centro norte de Santa Catarina e é um dos destinos turísticos mais visitados do Brasil, recebendo na alta temporada 2016/2017, 1.150.507 turistas (SECTUR, 2016).

O mar da Praia Central, principal do Balneário, é calmo e sua área de areia extensa, clara, densa, a qual permite a caminhada sem grandes

dificuldades. O clima é considerado ameno e, no verão a média é de $25^{\circ} \mathrm{C}$.

Em relação ao conforto ambiental, constatou-se que a exposição ao sol e às altas temperaturas, a difícil caminhada entre os guarda-sóis e, em alguns casos na água, a falta de banheiros públicos são os principais problemas e dificuldades encontrados e/ou citados pelos ambulantes.

Para amenizar a exposição e se protegerem do sol, 95\% dos entrevistados afirmaram que utilizam filtro solar, geralmente fornecido pela Prefeitura Municipal. Apesar do uso do filtro, devido à grande exposição solar e falta de reaplicação de acordo com a indicação dos fabricantes, $25 \%$ dos entrevistados possuem algum tipo de problema de pele em decorrência da exposição solar e $60 \%$ dos entrevistados já possuíram problemas e realizaram ou estão em fase final de tratamento. Já os óculos de sol são utilizados por $65 \%$ dos ambulantes entrevistados, sendo que todos $16^{\circ}$ Ergodesign - Congresso Internacional de Ergonomia e Usabilidade de Interfaces Humano Tecnológica: Produto, Informações Ambientes Construídos e Transporte

$16^{\circ}$ USIHC - Congresso Internacional de Ergonomia e Usabilidade de Interfaces Humano Computador

CINAHPA | 2017 - Congresso Internacional de Ambientes Hipermídia para Aprendizagem. afirmaram que utilizam mesmo em dias de nublados. Apesar disto, devido à exposição dos olhos à alta luminosidade, assim como em decorrência da utilização de óculos falsificados ou sem proteção adequada, $60 \%$ dos entrevistados afirmaram que possuem algum tipo de problema de visão ou irritação nos olhos, resultantes da exposição solar, falta de proteção e/ou contato com a areia.

Além dos óculos, tanto o chapéu, quanto o guarda sol acoplado ao cabide carregado são acessórios utilizados por $85 \%$ e $60 \%$ dos ambulantes que buscam uma proteção extra nos dias ensolarados. O calçado preferido dos ambulantes, por sua vez, é o chinelo de dedo, geralmente o de borracha. Este tipo de proteção para os pés é utilizado por $65 \%$ dos entrevistados. Já a sandália presa aos pés e o tênis, que seriam mais indicados para este tipo de caminhada, são utilizados por menos de $10 \%$ dos que responderam o questionário.

Apesar de esquentar os pés e parecer menos confortável para o ambiente em questão, devido às longas caminhadas e atrito com a areia, a proteção para os pés com tênis ou calçado fechado mostrase de importância considerável para facilitar a caminhada, diminuir os impactos e atrito, assim como reduzir as dores nos pés relatadas por alguns trabalhadores.

Tratando-se das atividades, o trabalho de ambulante envolve uma sequiência de tarefas, que se inicia com a o recebimento das cangas e saídas de praia do fornecedor e distribuição em um cabide de madeira.

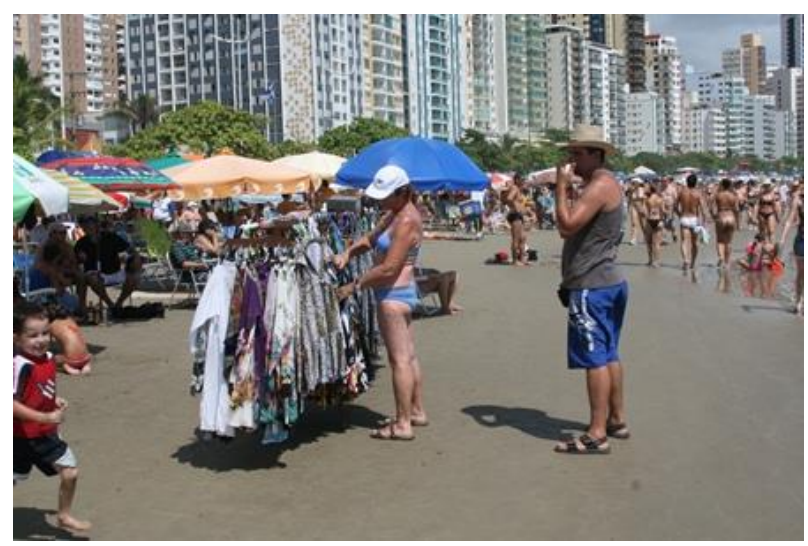

Figura 01. Ambulantes trabalhadores da Praia de Balneário Camboriú durante a temporada. Fonte: Acervo Pessoal, 2013. 


\section{$16^{\circ}$ \\ ERGODESIGN USIHC CINAHPA}

Com o cabide organizado, o vendedor ambulante chega à praia e caminha com o mesmo sobre um dos ombros, até clientes se aproximarem. A distancia média percorrida pela maioria dos entrevistados é de três quilômetros, o que corresponde a aproximadamente metade da orla da Praia Central.

Essa distância é percorrida durante todo o dia, em uma jornada de trabalho que para a maioria dos entrevistados chega a 8 horas na praia. Os outros $35 \%$ chegam a trabalhar até 15 horas, em uma jornada que se estende para o período noturno, onde todos se concentram próximo a uma praça da cidade, na qual existem algumas atividades culturais, que reúnem um grupo considerável de turistas.

Apesar da distância percorrida e jornada de trabalho longa, mais da metade dos ambulantes não possuem intervalos oficiais para descanso ou almoço. Pequenos descansos ocorrem quando os clientes se aproximam e o ambulante solta o cabide. Os intervalos para almoço geralmente são curtos e não são acompanhados de descanso para a digestão. Aqueles que não possuem intervalo afirmaram que acabam se alimentando mal e em quantidades inadequadas, caso contrário não conseguiriam realizar a atividade imediatamente após a refeição.

Conforme afirmado anteriormente, durante a maior parte da jornada de trabalho, o ambulante carrega o cabide em seus ombros. Esse cabide utilizado para expor os produtos é feito de madeira e possui um apoio para o ombro em seu eixo, assim como dois pés para apoio no chão enquanto os clientes escolhem os produtos e/ou o ambulante descansa. $\mathrm{O}$ peso varia bastante de acordo com o trabalhador, seu sexo e sua estatura.

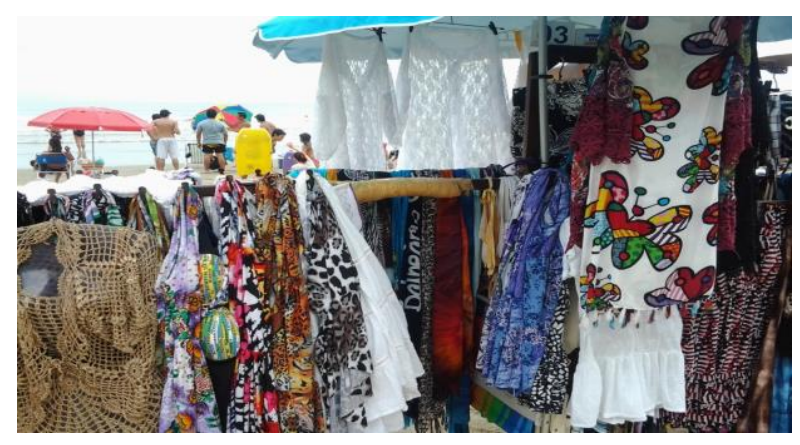

$16^{\circ}$ Ergodesign - Congresso Internacional de Ergonomia e Usabilidade de Interfaces Humano Tecnológica: Produto, Informações Ambientes Construídos e Transporte

$16^{\circ}$ USIHC - Congresso Internacional de Ergonomia e Usabilidade de Interfaces Humano Computador

CINAHPA | 2017 - Congresso Internacional de Ambientes Hipermídia para Aprendizagem.

Figura 05. Exemplo cabide médio com vara central onde o ombro do ambulante é apoiado. Fonte : Acervo Pessoal, 2013

\subsection{Análise comportamental e problematização}

Nessa etapa buscou-se compreender o comportamento dos usuários em relação às tarefas realizadas.

Tratando-se dos aspectos movimentais e posturais, verificou-se na maior parte dos entrevistados uma postura inadequada em três momentos críticos da atividade: o erguer e descer do cabide e o caminhar.

Durante o erguer e descer do cabide, ao invés de utilizarem a posição de agachamento, fazendo com que o peso do cabide seja distribuído pelo quadríceps, isquiotibais, glúteos máximo e coluna lombar, colaborando inclusive para o fortalecimento dos mesmos, grande parte dos ambulantes analisados somente flexionam levemente os joelhos, muitas vezes empurrando-os para dentro, gerando lesões musculares e articulares. Já durante a caminhada, a maior parte dos ambulantes compensa o peso unilateral nos ombros com um desvio inadequado da coluna, podendo gerar desgastes, quebra de vértebras, escoliose ou cifose.

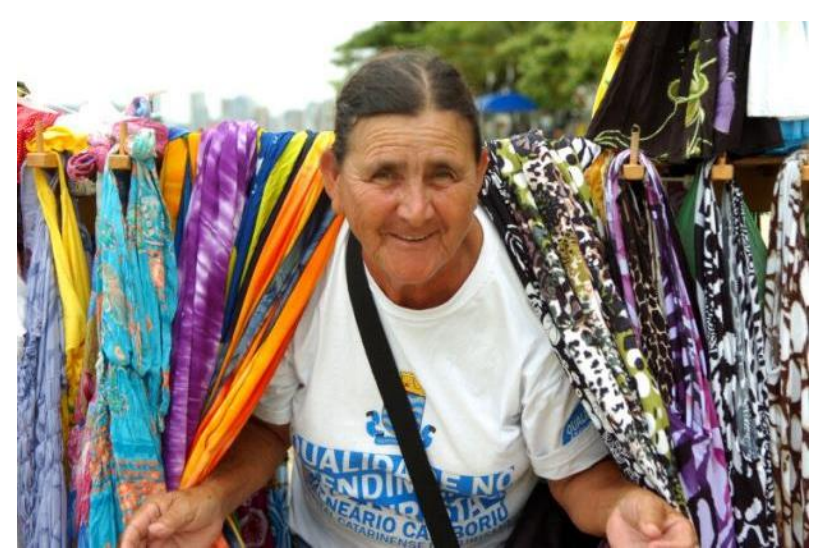

Figura 06. Ambulantes com seus cabines em Balneário Camboriú. Fonte:

http://osoldiario.rbsdirect.com.br/imagesrc/14275991.jp $\mathrm{g} ? \mathrm{w}=620$

Nos aspectos acionais manuais, durante a caminhada verificou-se que muitos trabalhadores utilizam as mãos como suporte extra para o cabide,
Realização:
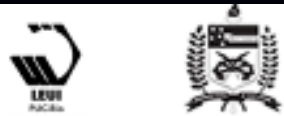


\section{$16^{\circ}$ \\ ERGODESIGN USIHC CINAHPA}

$16^{\circ}$ Ergodesign - Congresso Internacional de Ergonomia e Usabilidade de Interfaces Humano Tecnológica: Produto, Informações Ambientes Construídos e Transporte

$16^{\circ}$ USIHC - Congresso Internacional de Ergonomia e Usabilidade de Interfaces Humano Computador

CINAHPA | 2017 - Congresso Internacional de Ambientes Hipermídia para Aprendizagem. de modo a minimizar o peso depositado sobre um dos ombros. Esse posicionamento acaba forçando o ambulante a ficar com o punho torcido.

Em relação aos aspectos informacionais, devido à grande quantidade de cangas e saídas de praia em um mesmo cabide, formando diversas camadas, alguns ambulantes tem dificuldade na identificação de imediato algum modelo que possa ser aquele que o cliente busca e não consegue encontrar em uma primeira visualização do que está exposto. Tratando-se dos aspectos comunicacionais, por sua vez, o barulho proveniente da conversa da grande multidão que se concentra na orla durante a temporada, muitas vezes prejudica a comunicação entre o ambulante e o comprador, principalmente quando o ambulante é chamado por um cliente distante. Além dessa dificuldade de contato entre vendedor e cliente, pode-se acrescentar o reduzido espaço existente entre os guarda-sóis, o que impede o acesso as faixas mais "profundas" da areia, fazendo com que o ambulante por vezes tenha que caminhar na água.

Além de todos esses aspectos, acrescenta-se a possibilidade de acidentes, devido ao pequeno campo de visão do chão (a qual é bloqueado pela parte frontal do cabide) e a irregularidade da areia, que em alguns locais possuem buracos feitos tanto por crianças quanto pela própria força da água. Por fim, cabe caracterizar os problemas em relação aos aspectos naturais do meio onde é realizado o trabalho. $\mathrm{O}$ ambulante que trabalha na praia fica exposto aos mais diversos tipos de clima, variedade de temperatura e marés, as quais influenciam diretamente no grau de dificuldade na realização de suas atividades corriqueiras.

Todos esses aspectos e comportamentos verificados acabam resultando em conseqüências ao corpo e a saúde deste trabalhador. Do universo pesquisado, $70 \%$ dos que responderam o Questionário Nórdico afirmam que possuem dores durante o trabalho como ambulante.

Destas dores, a maior parte daquelas relatadas como sentidas nos últimos 12 meses durante o trabalho estão relacionadas à postura inadequada da caminhada e durante o erguer e descer do cabide, principalmente no tronco, coluna, coxas, joelho, quadril e cotovelo.

Já dentre os sintomas sentidos recentemente, a maior parte dos questionados respondeu que tanto a dor nas costas, quanto nos joelhos e cotovelos são aquelas mais presentes nos últimos sete dias e para $60 \%$ dos entrevistados essa dor impede ou restringe a realização do trabalho.

Apesar dessa expressiva quantidade de ambulantes que sentem algum tipo de dor em decorrência do trabalho realizado diariamente, apenas $35 \%$ afirmaram que consultaram um médico para uma avaliação.

Por outro lado, 55\% afirmaram que tomam antiinflamatórios ou analgésicos para aliviar as dores sentidas, demonstrando que parte dos ambulantes, por não possuírem plano de saúde e/ou acesso facilitado ao atendimento médico, se automedicam ou não dão devida importância aos sintomas apontados, ainda que os mesmos interferem ou restringem as atividades. Apesar das dores sentidas, em relação à carga física e emocional geradas pela atividade exercida, somente $40 \%$ dos entrevistados relatou que se sentem cansados somente no período entre novembro e janeiro, período de maior volume de trabalho.

Por fim, quando questionados sobre o grau de satisfação pessoal em realizar suas atividades, $70 \%$ afirmam que se sentem satisfeitos em realizarem as vendas na praia e pretendem continuar a atividade, pois além da renda obtida, eles acabam conhecendo pessoas de vários locais, que visitam a cidade. Ressalta-se, porém, que alguns dos ambulantes comentaram que os dias de extremo calor ou chuva afetam sua motivação para o trabalho.

\section{Sugestões e recomendações}

A análise permitiu a proposta de algumas recomendações que buscam contribuir para a diminuição dos males causados pelas atividades exercidas pelos ambulantes:

1) $O$ uso de filtro solar pode reduzir a incidência de problemas de pele, principalmente na Região Sul, onde a ocorrência de câncer de pele é alta. A exposição ao sol deve ser evitada no período das $10 \mathrm{~h}$ às $16 \mathrm{~h}$. Mesmo durante o horário adequado é necessário utilizar a proteção adequada como: chapéu, guarda-sol, óculos escuros e filtros solares com fator de proteção adequado ao ambiente e tipo 


\section{$16^{\circ}$ \\ ERGODESIGN USIHC CINAHPA}

$16^{\circ}$ Ergodesign - Congresso Internacional de Ergonomia e Usabilidade de Interfaces Humano Tecnológica: Produto, Informações Ambientes Construídos e Transporte

$16^{\circ}$ USIHC - Congresso Internacional de Ergonomia e Usabilidade de Interfaces Humano Computador

CINAHPA | 2017 - Congresso Internacional de Ambientes Hipermídia para Aprendizagem. de pele.

2) Os óculos solares devem ser utilizados por $100 \%$ dos vendedores ambulantes, tanto em dias de sol, quanto em dias nublados. Cabe ressaltar que óculos de sol falsos ou de baixa qualidade, não filtram o espectro total dos raios UVA e UVB, aumentando significativamente a possibilidade do surgimento de doenças.

3) O trabalho na praia, principalmente com terreno desigual traz demandas específicas quanto à mecânicas no caminhar. Diante disso, além da utilização de tênis ou sapato fechado, é recomendado a realização de exercícios de alongamento e fortalecimento muscular para evitar lesões musculares e articulares.

4) Em relação ao peso a ser carregado, para que se minimize os problemas nos ombros e na coluna, genericamente pode-se estimar que o ambulante deve levantar no máximo $10 \%$ de seu peso.

Todavia, acordo com a Consolidação das Leis do Trabalho (CLT), o brasileiro pode carregar até $60 \mathrm{~kg}$. Apesar desta estimativa, cabe ressaltar que o peso a ser carregado pode variar com o tempo que vai ser empregado para o seu deslocamento, o esforço que vai ser feito para retirá-lo de onde está colocado, e a forma com que ele vai ser conduzida pelas mãos.

5)As posturas de trabalho devem ser verificadas de modo a se evitar as dores e lesões. Ao invés de apoiar somente em um dos ombros, o cabide deve possuir uma base de modo que se consiga apoiar o mesmo em ambos os ombros, ou ainda, $o$ ambulante deve revezar entre os dois lados para evitar sobrecarga unilateral.

6) No Brasil, a jornada de trabalho é regulamentada pela Constituição Federal em seu art. $7^{\circ}$ XIII e a CLT art. 58, não pode ultrapassar 8 horas diárias, ainda que o período de permanência dos turistas na praia seja maior. O ideal é concentrar a jornada nos horários de maior venda. 7) Intervalos para almoço e/ou refeições são de extrema importância para uma alimentação correta assim como para se evitar a congestão, que é uma alteração ou paralisação do processo de digestão, a qual pode ocorrer quando se pratica exercícios físicos intensos após as refeições

8) No momento em que for erguer ou descer o cabide para os clientes, o ambulante deve utilizar posturas adequadas, como o agachamento, de modo a distribuir a carga evitando danos à coluna, ao joelho e à lombar.

9) Durante o percurso, o cabide deve possuir apoio suficiente nos ombros e preferencialmente devem ser incluídas alças para maior firmeza com o auxilio das mãos, sem a torção dos punhos, a qual pode gerar lesões por esforço repetitivo.

10) Em relação aos aspectos informacionais, os cabides devem ser organizados seja por cor, tipo ou modelo existente, de modo a facilitar a atividade do ambulante no momento em que procura alguma peça para o cliente.

11) Para se evitar acidentes decorrentes de buracos na areia, o campo de visão do ambulante deve ser aumentado, seja utilizando espelhos no cabide, seja criando brechas de visualização entre as peças expostas.

12) Em caso de qualquer tipo de dor ou desconforto, um profissional da saúde habilitado deve ser consultado e deve-se sempre evitar a automedicação.

\section{Considerações finais}

As entrevistas demonstram que apesar da grande incidência de dores nos últimos 12 meses de trabalho, os ambulantes permanecem por longos períodos nessa atividade e estão satisfeitos com o trabalham que realizam.

Como o ambiente não pode ser considerado uma variável a ser alterada, para aperfeiçoar o trabalho dos ambulantes, as sugestões apresentadas buscaram instruir tanto em relação à postura correta quanto a algumas atitudes que podem minimizar os danos à sua saúde.

Em relação ao cabide utilizado, um estudo antropométrico mais aprofundado pode servir de base para uma futura proposta de produto, que vise facilitar o trabalho deste grupo tão presente em nossas praias.

\section{Referências bibliográficas}

ALTMAN, I., \& CHEMERS, M.. Culture and environment. Monterey, CA: Brooks/Cole, 1980.

BELL, Paul; GREENE, Thomas C.; FISHER, Jeffrey D.; BAUM, Andrew. Environmental 


\section{$16^{\circ}$ \\ ERGODESIGN USIHC CINAHPA}

Psychology. Philadelphia: W. B. Saunders Company, 1978.

BRASIL. Constituição (1988). Constituição [da] Republica Federativa do Brasil. Brasília, DF: Senado Federal.

GUÉRIN, F. et al. Compreender o trabalho para transformá-lo: a prática da ergonomia.

Tradução: Giliane M. J. Ingratta, Marcos Maffei. São Paulo: Edgard Blücher, 1997.

IIDA, I. Ergonomia: Projeto e produção. São Paulo: Ed. Edgard Blucher, 1990.

LAVILLE, A. L'ergonomie. Paris: PUF, $5^{\mathrm{a}}$ ed, 1993.

MERINO, E.A.D. Efeitos agudos e crônicos causados pelo manuseio e movimentação de

cargas no trabalhador. Dissertação de Mestrado em Engenharia de Produção e Sistemas, UFSC:

Florianópolis, 2006.

MONTMOLLIN, Maurice de. A Ergonomia, tradução de Joaquim Nogueira Gil. Lisboa: Instituto Piaget, 1990. 160 p.

SECTUR, Secretaria de Turismo e

Desenvolvimento Econômico. Camboriú registra crescimento no número de turistas nesta temporada. Disponível em:

http://www.secturbc.com.br/turismo/pt$\mathrm{br} /$ noticia/balneario-camboriu-registracrescimento-no-numero-de-turistas-nestatemporada\#sthash.dDrDCDVr.dpuf. Acesso em 15/03/2017. $16^{\circ}$ Ergodesign - Congresso Internacional de Ergonomia e Usabilidade de Interfaces Humano Tecnológica: Produto, Informações Ambientes Construídos e Transporte

$16^{\circ}$ USIHC - Congresso Internacional de Ergonomia e Usabilidade de Interfaces Humano Computador

CINAHPA | 2017 - Congresso Internacional de Ambientes Hipermídia para Aprendizagem. 